\title{
Multi-district Rotational Schemes for Post-graduate Trainees in Psychiatry
}

SoM D. SONI, Salford Rotational Training Scheme, Hope Hospital, Salford; ALAN TAIt, North Manchester Rotational Scheme, Tameside General Hospital, Ashton-under-Lyne; SAlly PIDD, Lancaster Moor Rotational Scheme, Lancaster Moor Hospital, Lancaster, and David P. Goldberg, Professor of Psychiatry, Chairman, Specialty Training Group, University of Manchester, Manchester

The exercise of hospital accreditation by the Royal College of Psychiatrists has resulted in a significant improvement in the standards of psychiatric training in this country. ${ }^{1}$ The North West, more than any other region, adopted the policy of District General Hospital psychiatry ${ }^{2}$ in the sixties which had the effect of creating small psychiatric units, unable to muster enough resources, to provide comprehensive training programmes by themselves. These developments have highlighted the problems of organising viable rotational schemes for training in psychiatry. 3.4 .5

There are many theoretical advantages in encouraging multi-district rotational schemes, in particular: (1) Such collaboration between districts allows pooling of resources which are usually scarce and gives the trainees access to better facilities. (2) It allows a larger number of trainees to be incorporated into the rotation, making it more viable, so that meaningful training programmes can be developed. The trainees have greater choice of specialist and generalist options allowing a broader base for their training. (3) An improvement in the quality of the training scheme leads to a corresponding improvement in the calibre of the trainees.

This paper describes the setting up, organisation and the problems of multidistrict rotational schemes in the North West. The discussion below is based on experience gained by the authors and is extracted from a series of discussions during 1985, between clinical tutors and the Specialty Training Group of the University of Manchester. Unless specifically indicated, the word 'trainee' in the text applies to both senior house officers (SHOs) and registrars.

\section{Present rotational schemes}

The first formal rational training scheme to be established in the North West, in the early 1970s, was centred on South and Central Manchester. This scheme is now well established and consists of general psychiatry posts mainly at Withington and Cheadle Royal Hospitals and specialist posts in many hospitals in the region including Prestwich Hospital. However, the number of trainees in the scheme soon reached 30 and the scheme became administratively difficult to manage; it was already covering an area stretching from Macclesfield to Prestwich and later to Blackburn. The Specialty Training Group accordingly decided to set up local rotational schemes, each covering relatively small geographical areas of a more manageable size.

The Salford Scheme is a four year rotation in which the first two years are spent in general psychiatry and the last two in specialist units. It is administered by a Postgraduate
Educational Committee whose members (clinical tutors from all four districts participate and a representative of junior doctors) meet every month and oversee all matters concerned with the rotation, such as review of trainees' progress, their allocation to various firms, the content of local teaching programmes and even complaints about trainees and trainers. The North Manchester Scheme is a three and a half year rotation in which the last 18 months are in specialist departments. It has a similar committee of representatives from each participant district including tutors. The Lancaster Moor Scheme is a comparatively smaller scheme, with seven rotational posts. The organisation is, therefore, simpler and the clinical tutor has the sole responsibility for its administration. It is different in having a geographically large rural catchment area with clinics in places far away from base hospital.

Rotational schemes that had access to a mental hospital have been more successful because, for historical reasons, these hospitals have had many resources not available elsewhere and some aspects of psychiatry, e.g. rehabilitation, had already been developed there. Besides, during the past decade, many mental hospitals have become repositories of Regional specialist facilities, and access to them has been essential for schemes seeking a varied experience for their trainees.

\section{Organisation of rotational schemes}

In nearly all cases, the schemes have resulted from failure of districts to provide adequate training by other means. Allowing trainees to visit specialist units two sessions a week was inevitably unsuccessful and has been a wasteful exercise. Internal rotation in the hospital was equally unsuccessful. Shared posts (either between two specialist units or between one generalist and one specialist) have also proved unworkable. The only alternative appeared to be collaborative rotational schemes incorporating $\mathrm{SHOs}$ and registrars.

Very early in the development of such schemes, it was noticed that registrar posts were, mainly, attached to general psychiatry firms, and the only way of broadening the training base was to reallocate them to specialist departments. The North Manchester Scheme avoided this by getting three new registrar posts, just before the present freeze, for their final specialist year. In other districts, reallocation has been the main mechanism of providing specialist experience to the trainees. These changes have meant that the general psychiatrists from nearly all districts have had to 
'sacrifice' their posts (particularly registrars) to the specialist units. This appears to have produced the desired effect and initial fears, that general psychiatry services may suffer in the process, have not been borne out.

There are no firm guidelines about the duration of each rotation. Our experience has shown that four month placements in specialist units have been too short and are now being changed to six months. Traditionally most schemes have been of a three year duration; our experience suggests that this gives the trainees barely enough time to obtain their membership examination. In North Manchester and Salford, the total duration of the schemes has now been increased to up to four years. Most districts cannot provide extensive exposure to specialist experience. By collaborating, some districts in North West have been able to plan specialist services in such a way that the rotational scheme has acquired a number of different posts, thereby increasing the specialist options available to the trainees. Inevitably, some trainers have been excluded by such arrangements, but not every consultant need be a trainer with automatic right to have a psychiatric trainee.

The number of junior doctors in a scheme has often determined the success or otherwise of the rotation. Single district rotations often have too few to produce a viable scheme. There is no 'critical' number for proper functioning of a rotation; any number less than eight in a three year rotation (as in the Lancaster Moor Scheme) has put considerableconstraints on the tutor. To have too many trainees has also produced problems (law of diminishing returns!). The Salford scheme has 22 doctors and is already too large and unwieldy. The North Manchester scheme has eight and is perhaps more manageable but at the expense of reduced width of specialist experience for their trainees. The ratio of SHOs to registrars needs to be such that it would allow the scheme to operate without silting up with too many SHOs waiting to be promoted or competing for a smaller number of registrar posts. To avoid high discrepancy in numbers, between the two grades, a proportion of SHO posts in most schemes, have been allocated to 'vocational training schemes' (see below).

The unwillingness of some consultants to participate in training programmes has been due either to lack of interest or of time or both. The College guidelines, about the kind of supervision expected of the trainers, are clear and succinct. ${ }^{6}$ Many consultants have genuinely wanted information on this aspect which can be easily provided. The Junior Doctors Committees continuously review the training received in different firms, including specialities, and this can be used by the tutor to instigate change towards improving the overall quality of training. In districts where there has been a sympathetic and a receptive administration, sensitive to the needs of having a successful training programme, the evolution of a good training scheme has been smoother.

In arranging the rotation the tutors have had to take into consideration the needs and wishes of the trainee and match these with the wishes of and the training provided by the trainers. Inevitably, some slots have become more populas than others but this has been due more to the compatibility between the trainer and the trainee, than to the quality of training received. In Multi-District Schemes, contrary to general expectations, junior doctors have not been happy to move around hospitals at some distance from their base. In some districts the contracts for trainees are held at base hospital and annual recharge made to districts participating in the rotational scheme. From trainees' point of view, this has simplified the mechanics of the rotation.

The teaching has been designed to complement the MRCPsych course conducted by the Department of Psychiatry at the University of Manchester. This course has a modular structure and offers a choice of two modules on psychiatric topics each term. In some rotations, a separate tutor attached to the scheme oversees the teaching programme organised by the local clinical tutors in participant districts. Districts at some distance from the 'centre' have had problems with the MRCPsych course and have had to concentrate more on local programmes.

\section{Non-rotational training posts}

In almost all rotational schemes in the North West, SHOs outnumber registrars by three to one. The schemes, therefore, have a surfeit of SHO posts and many of these cannot be assimilated into training schemes if they are to be successful. There have been many innovative approaches to this problem; the most acceptable has been to allocate them for psychiatric training of other non-psychiatric vocations. Although the single most important group are SHO posts allocated to those intending to become general practitioners, we also provide training opportunities for community physicians, prison medical officers, community health doctors and even the occasional paediatrician and obstetrician. A further use of SHO posts has been for doctors wishing to give psychiatry a 'try' but who afterwards may decide to specialise in another subject.

The major problem with this approach has been that the training provided for psychiatric trainees is unsuitable for them. In the North West, this has been tackled by the Department of Psychiatry starting special 10 week courses directed specifically towards non-psychiatric trainees. Teaching on this course is heavily slanted towards the needs of future general practitioners, with major emphasis on interviewing techniques, management skills and the opportunity to have supervision on current patients receiving outpatient treatment on a weekly basis. The first course was well received and will be repeated in subsequent years. Similar courses in Mental Handicap for general practitioners, ${ }^{7}$ although different in structure and objectives, have also been shown to be successful. Posts allocated to these trainees have had to be modified to suit their special requirements.

\section{Future of trabned poychiatriats}

The changes outlined above may have improved the quality of training in psychiatry but it has also produced a problem which had not been foreseen. Most schemes in the North West are now producing well trained registrars with all the 
qualifications necessary to progress to senior registrar (SR) posts. The number of SR posts is limited and determined (probably rightly so) by the number of consultant posts available. Many registrars are now finding themselves in a situation in which they see no future for themselves.

The problem, in many ways, is a replication of what has so far been happening in main stream specialities in medicine. It would be far too easy to ignore the problem and let market forces determine their progress to SR posts. But this, we feel, would make no economic sense and a waste of time and good training and, sooner or later, this problem will have to be addressed. One solution may be to trim the training schemes so that the number of registrar posts more or less matches the number of SR posts. Perhaps some of these posts could be allocated to sponsored foreign medical graduates, which would not only alleviate this problem but would also be a source of considerable goodwill for British psychiatry abroad. Careful planning of careers for psychiatrists at an earlier stage will obviate much waste of human resource.

\section{Discussion}

The experience of developing comprehensive rotational training scheme in the North West has highlighted many factors that determine the success or otherwise of a multidistrict rotation. The inclusion of as many specialities as possible in the rotational scheme, even if this be at the expense of losing general psychiatry posts, considerably improves the options available to the trainees. Amongst factors that appear to be relevant are willingness of the tutor to impart information about training requirements to those who ask for it and a well organised machinery for review of trainees' and trainers' progress. The structure of medical staffing has needed to be overhauled in many of the North West schemes to get them off the ground. We have also found that large psychiatric hospitals invariably have more resources and facilities required for good comprehensive training programmes; where present, these can be tapped to improve training.

One problem of developing successful training schemes, paradoxically, has been, the surplus production of well trained psychiatrists. This, we suspect, is going to confront us nationally within a very short space of time. We feel that, this should be addressed systematically now if we wish to avoid unnecessary wastage of well trained manpower in psychiatry.

\section{REFERENCES}

'RAWNSLEY, K. (1984) The future of the consultant in psychiatrya report to the College. Bulletin of the Royal College of Psychiatrists, 8, 122-123.

${ }^{2}$ Freeman, H. L. \& Farndale, J. (1967) (eds.) New Aspects of Mental Health Services. Oxford: Pergamon Press.

${ }^{3}$ JONES, D. M. H. (1984) Accreditation and registrar training. Bulletin of the Royal College of Psychiatrists, 8, 180.

${ }^{4}$ LAUNER, M. (1984) The Approval Exercise-constipated chaos? Bulletin of the Royal College of Psychiatrists, 8, 74-75 and 8, 196 (Hollyman, J.)

'MackaY, A. V.P. (1984) A reply to the President's letter. Bulletin of the Royal College of Psychiatrists, 8, 62-64.

${ }^{6}$ SMith, E. B. O., Julier, D. L. \& SEAGER, C. P. (1963) A Handbook for Psychiatric Tutors. The Education Committee of the Royal College of Psychiatrists.

${ }^{7}$ Bicknell, J. (1984) Educational programmes for general practitioners and clinical assistants in the Mental Handicap Service. Bulletin of the Royal College of Psychiatrists, 8, 154-155.

\section{New Publications}

When the Talking Has to Stop, MIND's investigation into the closure of Banstead Hospital, is available from MIND Publications Service, 4th Floor, 24-32 Stephenson Way, London NW1 2HD, price £1.50. Further details: Chris Shaw or Harry Reid (telephone 01637 0741).

Course Organisers in General Practice, Occasional Paper 34, is available from the Central Sales Office, Royal College of General Practitioners, 14 Princes Gate, Hyde Park, London SW7 1PU, price $£ 4.50$, including postage. Payment should be made with order and cheques made payable to RCGP Enterprises Ltd. Visa and Access are welcome (telephone 01581 3232). Based on a series of detailed tables, this factual account will be of particular value to course organisers as it forms the most comprehensive and up-to-date information available on this subject. Enquiries should be addressed to: Dr A. H. E. Williams, The Medical Centre, Cleobury Mortimer, Nr Kidderminster (telephone 0299 27029).
Echo, the St George's Hospital Psychiatry Review, will appear twice annually and the first edition has been distributed to all psychiatrists throughout the SW Thames Health Region. A number of copies of the first edition remain and any psychiatrist who has not yet received a copy is invited to write to the Editors, c/o Clare House, St George's Hospital, Blackshaw Road, Tooting, London SW17. The Editors will also be pleased to receive requests for spare copies of the first edition from other agencies or individuals who might be interested.

The European Journal of Psychiatry is a new review which will be published quarterly in English to reflect the scientific activity of European psychiatrists. Contributions covering all aspects of psychiatry and the associated fields of biology, psychology and social sciences are invited. Correspondence, manuscripts and books for review should be addressed to the Editor-in-Chief: Professor A. Seva, The European Journal of Psychiatry, PO Box 6.029, 50080 Saragosse, Spain. 